\title{
New Vistas on Oxidative Damage and Aging
}

\author{
Rüdiger Hardeland ${ }^{*, 1}$ and Ana Coto-Montes ${ }^{2}$ \\ ${ }^{1}$ Johann Friedrich Blumenbach Institute of Zoology and Anthropology, University of Goettingen, Goettingen, Germany \\ ${ }^{2}$ Departamento de Morfología y Biología Celular, Universidad de Oviedo, Oviedo (Asturias), Spain
}

\begin{abstract}
Age-associated rises in oxidative damage are assumed to be a central phenomenon of aging. Their attenuation is an aim for both healthy aging and life extension. This review intends to critically discuss the potential of anti-oxidant actions, but even more to direct the attention to the modes of radical avoidance and to regulatory networks involved. Mitochondria seem to play a decisive role in radical formation and cellular decline. Avoidance and repair of disruptions in the electron transport chain reduce electron leakage and, thus, oxidative damage. Several low molecular weight compounds, such as melatonin, its metabolite $N^{1}$-acetyl-5-methoxykynuramine, resveratrol, $\alpha$-lipoic acid, and various mitochondrially targeted nitrones are capable of supporting mitochondrial electron flux. Some of them have been successfully used for extending the lifespan of experimental animals. Importantly, chemopreventive effects of these substances against cancer development should not be confused with a slowing of the aging process. We also focus on connections between these compounds and mitochondrial biogenesis, including the roles of sirtuins and signaling via peroxisome proliferator-activated receptor- $\gamma$ coactivator- $1 \alpha$, the participation of the circadian oscillator system in radical avoidance, as well as the potentially beneficial or detrimental effects of NO, as either a regulator or a source of mitochondrial dysfunction. Especially in the central nervous system, anti-excitatory actions by melatonin, kynurenic acid and theanine are discussed, which seem to prevent calcium overload that results in mitochondrial dysfunction. New findings on direct binding of melatonin to the amphipathic ramp of Complex I may indicate an additional regulatory role in the avoidance of electron leakage.
\end{abstract}

Keywords: Aging, anti-oxidants, electron leakage, melatonin, mitochondria, PGC-1 $\alpha$, sirtuins.

\section{INTRODUCTION}

Aging is a complex phenomenon, in which slow, lingering processes of steady declines in metabolism and physiological functions are superimposed by single events of deterioration, which are caused by diseases and followed by secondary impairments. In the worst case, infarction, stroke, renal failure or cancer, and sometimes also the medicinal treatment, represent profound individual catastrophies, which impair the function of organs and cells and, thereby, contribute to the acceleration of the more continual processes of aging, even if the primary treatment is per se successful. However, less severe diseases may also affect the health state in a way to make aging more rapidly progressing. Much of theoretical work has been published on the mechanisms of aging. Although the increase of age-related morbidity has some explanatory plausibility for the consequences of the step-wise events of impairment, it does not seem to fully comprise the causes and mechanisms of the more steady functional declines. This aspect is multi-faceted. It includes the maintenance of immunological functions for safeguarding the individual's resistance to germs and viruses [1,2], the preservation of healthy endothelial surfaces and also efficiently working mitochondria. In part, the organismal decline seems to be associated with reduced capacities for

*Address correspondence to this author at the Johann Friedrich Blumenbach Institute of Zoology and Anthropology, University of Goettingen, Goettingen, Germany; Tel: +49-551-395414; Fax: +49-551-395438; E-mail: rhardel@gwdg.de cell division because of telomer shortening, but even more with progressing losses of adult stem cells, which leads to a reduced capacity for tissue repair. However, this cannot be equally valid for every organ, because of enormous differences in the replacement of cells and the survival of partially dysfunctional cells. Despite this obvious diversity, the key to the slow processes of impairment has to be sought in the metabolism of an organism. This view is supported by the existence of aging-suppressor genes, such as those for sirtuins [3-8] and klothos [9-14], which act as cellular energy sensors and regulators of cellular and organellar functions.

A common theme to many of the age-related dysfunctions is the damage by reactive oxygen and nitrogen species (ROS and RNS). Different sources of these potentially damaging intermediates are of relevance. Oxidants induced especially by UV light are important to the skin. Macrophages and other oxidant-producing leukocytes can contribute to the damage of epithelial surfaces, and atherosclerotic incrustations lead to further damage by nitric oxide $(\cdot \mathrm{NO})$ derived free radicals, especially radical pairs formed from peroxynitrous acid ( $\mathrm{ONOOH} \rightarrow \cdot \mathrm{NO}_{2}$ and $\cdot \mathrm{OH}$, i.e., nitrogen dioxide and hydroxyl radical) or from the peroxynitrite- $\mathrm{CO}_{2}$ adduct $\left(\mathrm{ONOOCO}_{2}^{-} \rightarrow{ }^{-} \mathrm{NO}_{2}\right.$ and $\mathrm{CO}_{3}{ }^{-}$, i.e., nitrogen dioxide and carbonate radical) $[15,16]$. In this scenario, superoxide anions $\left(\mathrm{O}_{2}{ }^{-}\right)$required for peroxynitrite formation are generated at high rates in cells compromised by insufficient oxygen supply, whereas $\cdot \mathrm{NO}$ is produced in the partially unsuccessful attempts of causing vasodilation, and $\mathrm{CO}_{2}$ is present in supranormal concentrations because of the 
reduced blood flow [16]. If not formed in the oxidative burst of an activated leukocyte, the major sources of $\mathrm{O}_{2}{ }^{-}$are usually mitochondria. Electrons are leaking, mostly at Complexes I and III, when secondary bottlenecks transiently impede electron flux, e.g., at Complex IV under conditions of insufficient oxygen supply $[17,18]$. Also in other scenarios, electron leakage from mitochondria is a main cause of oxidant formation. $\mathrm{O}_{2}{ }^{-}$is converted to more destructive radicals, either via peroxynitrite or dismutation to $\mathrm{O}_{2}$ and $\mathrm{H}_{2} \mathrm{O}_{2}$, this latter compound being another source of the devastating $\cdot \mathrm{OH}$. Moreover, $\mathrm{CO}_{2}$ is abundantly available in the mitochondrial matrix, where it is produced. Therefore, elevated mitochondrial generation of $\mathrm{O}_{2}{ }^{--}$by electron leakage from the electron transport chain is likely to result in high rates of $\mathrm{ONOOCO}_{2}^{-}$formation and the radicals formed by its decay.

Mitochondrial dysfunction obviously occurs during normal aging, but seems to be cell type- or tissue-specific. It can even vary within a cell, as observed in cardiomyocytes, in which subsarcolemmal mitochondria did not show profound signs of dysfunction in the course of aging, whereas interfibrillary mitochondria exhibited severe decreases in Complex III and IV activities and increased electron leakage, mainly from the Qo site of Complex III. However, antioxidative protection especially of cardiolipin, which is required for the function of Complexes III and IV, largely restored interfibrillary mitochondrial activities [19-25].

The involvement of mitochondria in the aging processes has already been assumed in the earlier free radical theory of aging [26,27]. In its more recent versions, it has developed towards a model centered on mitochondrial damage and dysfunction [28-30]. The paradigm has meanwhile changed from the premises that these organelles are both major source and target of destructing radicals to the new perspectives of metabolism modification and avoidance of electron leakage. Therefore, the new questions to be answered are those of how mitochondrial function can be supported and maintained in the long run, how electron dissipation can be avoided, and which molecules may be suitable for this purpose.

\section{OXIDATIVE DAMAGE DURING AGING AND ITS RELATIONSHIPS TO CHRONOBIOLOGY}

Enhanced oxidative damage of membrane lipids and biological macromolecules during aging, including the consequences for cell death, are amply documented [31-48]. In the absence of experimentally induced radical formation, e.g., for testing the rises in vulnerability, it is frequently difficult to distinguish between damage as a cause, a cophenomenon and a consequence of aging processes. Presumably, all of these possibilities have to be equally considered. Diseases may not only weaken the body's resistance, but also lead to enhanced radical generation. The causes may be either cell damage and death or oxidants formed in the organism's defense responses. Rises in oxidant formation, as occurring in the course of aging, may increase the dysfunction of structures relevant to free-radical generation, in particular, mitochondria, so that a vicious cycle between cause and consequence is initiated.
It is not the aim of this review to repeat discussions on the numerous findings concerning progressive oxidative damage during aging, nor to refer to the countless attempts of pharmacological interventions. However, some aspects shall come into focus which are, in the broadest sense, bridging chronobiology and oxidant generation.

Damage to mitochondria, a major source of oxidants, during aging is a long-known phenomenon [19-28,44,49]. This damage has been found to progress more rapidly in senescence-accelerated mice [50]. However, caution is due with regard to interpretations based on the original freeradical theory of aging, including the classic assumptions of a purely mitochondrial vicious cycle. It has been criticized with good reason that many of such conclusions are derived from pharmacological experiments, which are far from real life during normal aging [51]. Moreover, investigations in mitochondrial DNA (mtDNA) mutator mice revealed that, despite amplified mitochondrial mutations in the course of aging, no increased ROS production was demonstrable [52]. This should mean that the original assumption of mitochondrial mutations as a source of enhanced ROS generation is not supported. Moreover, it seems important to dismiss the idea that mtDNA were particularly vulnerable because of a lacking chromatin structure. In fact, mtDNA is densely loaded with proteins, in particular, the mitochondrial transcription factor A (TFAM), a high mobility group (HMG) related molecule, which also fulfills functions in nucleoid structure, damage sensing and mitochondrial replication [5356]. Several other proteins, including anti-oxidant enzymes, are bound to the mtDNA as well [56]. Nevertheless, the lack of a clearly demonstrable relationship between mitochondrial mutations and radical generation does not immediately imply that a vicious cycle between mitochondrial dysfunction and free radical production does not exist. It only does not include the damage to mtDNA as a necessary component. It rather seems that enhanced radical formation causes damage to the electron transport chain (ETC). This leads, in turn, to enhanced electron leakage and, thus, oxidants affecting both the ETC and, upon dissipation into other compartments, the rest of the cell. Therefore, the vicious cycle should be understood as a self-enhancing, in the cybernetic sense "positive", feedback loop between electron leakage and the causes of further leakage from the damaged ETC.

The relationship between radical formation to chronobiology has several aspects, (i) age-associated declines in the amplitude of circadian oscillations, (ii) dysphasing, as occurring by progressive shortening of the spontaneous circadian period and leading to age-related advances of the clock, and (iii) the steady decline in the nocturnal rhythmic secretion of melatonin.

The importance of circadian rhythms in aging may not be a matter of general awaress. Nevertheless, the evidence for its relevance is convincing. An important, but frequently overlooked finding was obtained in aged Syrian hamsters, which received transplants of suprachiasmatic nuclei $(\mathrm{SCN})$ [57], the hypothalamic structures which represent the circadian pacemaker. Although such a transplant cannot form a structure fully equivalent to the recipient's own SCN, it did not only restore the circadian time pattern of locomotor activity, which had previously become irregular and partially 
disrupted in the aged animals, but it also extended the lifespan of the recipients [57].

Relationships between circadian rhythms, oxidants and anti-oxidative protection are obvious under various aspects. Oxidant formation is rhythmic, already as a result of rhythms in metabolism, in light-exposed species also as a consequence of radiation. Organisms have adapted to this periodic challenge by generating circadian oscillations of anti-oxidant enzymes and concentrations of low molecular weight antioxidants (LMWAs), findings that were obtained in many different species from phylogenetically distant taxa, including unicellular algae, invertebrate and vertebrate animals [58]. In Drosophila melanogaster, a rosy mutant $\left(r y^{506}\right)$ unable to synthesize the endogenous LMWA urate showed strongly elevated levels, enhanced circadian amplitudes and alterations in the temporal pattern of protein carbonyl, an oxidative protein modification [59]. The relevance of circadian rhythms for attenuating oxidative damage became even more evident in animals carrying mutations in clock genes of the circadian core oscillator. In the arrythmic per ${ }^{0}$ mutants of $D$. melanogaster, protein carbonyl did not only show the absence of a circadian pattern, but was, additionally, markedly elevated [59]. Moreover, per ${ }^{0}$ flies exhibited an elevated susceptibility to exogenously induced oxidative stress [60]. Interestingly, increased oxidative damage to proteins was also observed in the short period mutant pers, when the animals were maintained under a light/dark cycle of 12:12 hours, i.e., a Zeitgeber period substantially deviating from the spontaneous period of the per $\mathrm{S}$ animals [59]. A corresponding observation was made in another short period mutant of a different organism, the tau mutant of the Syrian hamster. In this case, both protein carbonyl and lipid peroxidation were strongly elevated in the Harderian gland [61], an organ that is particularly vulnerable to oxidative damage [62]. Collectively, these findings indicate that not only the mere existence of a circadian rhythm is decisive for avoiding damage by oxidants, but also an appropriate phasing that allows detoxification of free radicals in those circadian phases when enhanced anti-oxidative protection is required, e.g., in conjunction with elevated metabolism. Moreover, findings in tau hamsters revealed a relationship to lifespan. Again, the aspect of appropriate rhythmic coordination comes into focus: Homozygous tau hamsters showed only a moderate statistical tendency of reduced lifetime (mean survival 15.8 vs. 17.5 months in wild-type], but heterozygous tau animals had a substantially shortened life span (10.9 months) [57]. This may be taken as a sign of internal malcoordination, due to differently acting oscillators.

Enhanced oxidative damage because of dysphased rhythms may not only occur in clock mutants, but also result from circadian phase shifts, as occurring in shift work or after transmeridian flights. In fact, repeated phase shifts were already shown decades ago to reduce the lifespan of flies [63]. Similar results were obtained in cardiomyopathic hamsters [64]. Shift work as a source of health problems is beyond any doubt [65-70] and may also affect longevity, at least in a subpopulation of individuals. However, this statement should not be misunderstood in terms of an oversimplification, since the impairment by shift work cannot be reduced to oxidative stress. Many other factors, such as sleep difficulties, associated problems of working conditions, and the role of circadian clock genes in preventing cancer contribute to statistically demonstrable health problems. The relationship between circadian dysregulation and cancer has received substantial support during the last years, After the original discovery that mice carrying a mutation in the per 2 gene are cancer-prone [71,72], numerous studies have now shown that several core oscillator proteins, including their variants, such as PER1, PER2, PER3, CRY1, CRY2, CLK, BMAL1 and CK1 1 are downregulated in various forms of cancer, and/or act as cancer suppressor genes and sensors of DNA damage [73-82]. Although it is far from being clear to what extent oxidative stress may be involved in this phenomenology, and although down-regulation of clock genes may be largely due to hypermethylation in the respective promoters $[73,83,84]$, the consequence of the circadian dysregulation is unavoidably an insufficient management of redox control, resulting in increased oxidative damage and higher probability of mutations.

Another aspect of circadian rhythmicity in relation to redox balance concerns melatonin. When thoroughly analyzed, this turns out to be a highly multi-faceted host of actions. In its role as a hormone of the pineal gland, melatonin acts as a regulator of numerous circadian functions. In its multiple roles as hormone, tissue factor, paracoid and autocoid [85], it also acts as an agent protecting against oxidative damage [86-95]. Various modes of action have been identified at different levels, from anti-excitatory/antiexcitotoxic and anti-inflammatory effects to regulation of anti- and pro-oxidative enzymes and direct radical detoxification, as summarized elsewhere [91,96]. Moreover, melatonin has profound actions on mitochondria and, thereby, strongly influences electron flux and leakage [17,18,58,97105]. Importantly, such findings were not only obtained under experimental conditions designed to challenge mitochondrial functions, but also in otherwise untreated animals. Beneficial effects on mitochondrial electron flux, respiratory efficacy and avoidance of damage to the ETC were especially observed in aged animals [99-101,106-112].

In the relationship between melatonin and aging, a crucial observation is the age-dependent decline in the nocturnal peak of melatonin secretion by the pineal gland. Although this is not equally pronounced in every individual, it is clearly demonstrable on a statistical basis and can be described as a dramatic change occurring in the majority of subjects [113-123]. The waning nocturnal melatonin peak has been interpreted as a consequence of general circadian deterioration, largely caused by progressing dysfunction of the pacemaker [124]. This may not be the only possible reason, since the onset of the decrease is already observed in middle-aged subjects $[118,119,121]$, in which deteriorations of pacemaker function are not yet obvious. Nevertheless, the changes in melatonin may strongly contribute to a weakening of the intra-organismal circadian organization and to losses in the efficacy of protective functions, at the levels of anti-oxidative defense, the immune system and mitochondria as well. 
RADICAL DETOXIFICATION, RADICAL AVOIDANCE AND RESISTANCE TO OXIDATIVE STRESS

The classic view of anti-oxidative protection is based on the assumption that radicals already formed have to be detoxified as efficiently as possible. This concept was supported by numerous pharmacological investigations, in which oxidants or oxidant-generating compounds were administered and their deleterious effects antagonized by usually unphysiologically high quantities of radical scavengers. Although such approaches are not without value, they may tell little about the processes underlying the aging process. They may be, in part, helpful in the combat against chronic inflammation associated with aging, but the aging process per se, in terms of a steady, lingering decline may remain unaccessible. In fact, the idea of prolonging life by overexpression of anti-oxidant enzymes has been only of limited success, and some of the initial reports on efficacy were later corrected or withdrawn. Moreover, knockout mice for major anti-oxidant enzymes, including those located in mitochondria, frequently failed to substantially decrease longevity, although oxidative damage to DNA and the incidence of cancer were enhanced [125-128]. Radical detoxification by scavengers and anti-oxidant enzymes is certainly a necessity, and a deficiency of anti-oxidants, e.g., by malnutrition, will cause the development of diseases, but, in relation to aging, this does not seem to touch the core of the problem. A possible access to unveiling the relevant processes may be sought in the comparison between longlived and short-lived species of approximately same size. In the past, differences in the efficacy of the radical-detoxifying enzymes have been in the focus and several reports have, in fact, pointed into this direction. Although this may contribute to longevity, it does not necessarily identify the crucial differences. In a recent study, muroid species of similar size, but differing considerably in lifespan were compared, the white-footed mouse (Peromyscus leucopus) and deer mouse (Peromyscus maniculatus) with a maximal lifespan of up to 8 years and the house mouse (Mus musculus) having a maximal lifespan of 3.5 years [129]. Although Peromyscus was shown to possess a more efficient anti-oxidant defense than Mus, two additional features became evident, namely, a superior DNA repair system, and a lower rate of mitochondrial oxidant formation. A more pronounced oxidative stress resistance was also reported for two other small, longlived mammals, the naked mole rat (Heterocephalus glaber) and the little brown bat (Myotis lucifugus) [130].

The triad of anti-oxidative defense, radical avoidance and oxidative stress resistance may be a key to especially healthy aging, but the relative contribution to lifetime remains to be clarified. In the cases of anti-oxidative protection and stress resistance, it is of utmost importance to distinguish between chemopreventive effects of anti-oxidants and changes in the aging process itself. This is of particular relevance in the use of inbred laboratory mouse strains, in which mortality from cancer prevails and, therefore, apparent changes in average lifespan are often caused by a reduction or delay of carcinogenesis [131]. However, in conjunction with the chemopreventive effects, a more youthful appearence of aging mice has been observed when compounds such as melatonin [29,132] or resveratrol [133] were administered, even in those investigations in which no significant effects on lifespan were demonstrated. Therefore, natural compounds or drugs that reduce oxidative damage can be of value for healthy aging, even in the absence of life extension.

However, these considerations clearly indicate the premier importance of selecting a suitable object for aging studies. In organisms or strains in which cancer is not a major cause of death and, therefore, chemoprevention not decisive, effects on lifespan may be entirely different. This is of particular relevance in the case of the highly pleiotropic agent melatonin, which is not only a pineal hormone but also present in various tissues, often at much higher quantities than in the pineal gland $[85,93,96,132,134]$. The selection of senescence-accelerated mice, SAMP8, which can be also compared with SAMR1, a normally aging strain carrying the same genetic background [135], can lead to results substantially different from those obtained in other strains. In SAMP8 mice, melatonin caused a clearly demonstrable prolongation of life [111]. A main question raised by the studies on SAMP8 is that of the reasons for the more rapid aging. These may not be identical with the normal causes of aging, although such an idea is highly attractive. As an example, one should remember progerias caused by mutations in lamin genes [136,137]. No one would assume that breakdown of the nuclear lamina could be a major cause of normal aging, despite the enormous acceleration of aging in these laminopathies. In SAMP8, a higher sensitivity towards oxidative damage was demonstrated [138]. Therefore, anti-oxidant treatment should be effective, including the possibility of reducing oxidative damage by radical avoidance, but the question remains whether it counteracts the normal aging process or "only" a cause of accelerated aging. Nevertheless, as long as this question has not been decided, studies on senescence-prone mice remain of high gerontological interest.

SAMP8 mice may also provide substantial information to a more comprehensive understanding of aging since they exhibit more rapidly developing changes in mitochondrial metabolism, which are clearly reduced by melatonin. This aspect will not be discussed here in any detail, because of a parallel publication by another group on this issue. As outlined in other reviews dealing with mitochondrial function and melatonin $[17,18,58]$, numerous results collectively show that changes observed at advanced age of the senescence-accelerated animals are reverted or attenuated by this indoleamine, such as, reductions in the respiratory control index (RCI); in state 3 respiration; in dinitrophenoluncoupled respiration, which reflects to some extent the respiratory capacity; in the ADP/oxygen ratio; in the ATP level; in the activities of Complexes I and IV. However, it is necessary to distinguish in studies on SAMP8 mice between processes occurring during aging in otherwise unchallenged animals and those intending to identify alterations in vulnerability, inducibility of apoptosis, and effects of inflammation. Though all these latter changes may be relevant in a specific context, they may not properly reflect the aging process per se.

Although caution is due concerning the very meaning of experimental interventions in senescence-accelerated mice, these animals provide valuable hints on radical avoidance, since they show age-related mitochondrial malfunctions in electron flux and energy efficiency, which are associated 


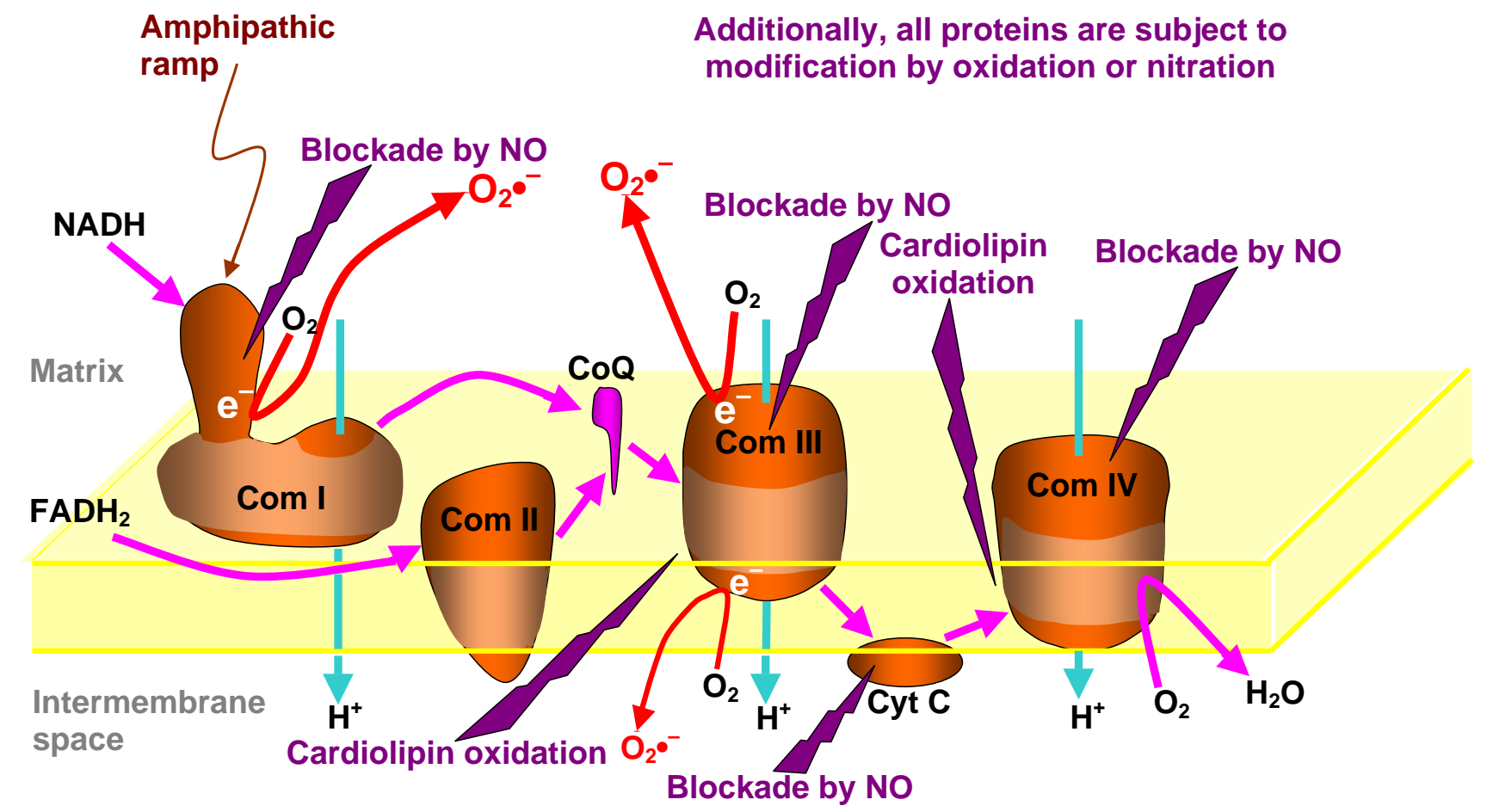

Fig. (1). The vulnerable sites of the mitochondrial electron transport chain (ETC) and the main sites of electron leakage. Arrows in pink color: electron flux through the ETC; red arrows: superoxide formation by electron donation to $\mathrm{O}_{2}$; flashes and text in violet color: effects leading to interruption of the electron transport and enhanced electron dissipation. The amphipathic ramp of Complex I is particularly vulnerable to modifications because of its exposure to reactive intermediates arriving from the aqueous matrix. Abbreviations: Com $=$ Complex; $\mathrm{CoQ}=$ coenzyme $\mathrm{Q} ; \mathrm{Cyt} \mathrm{C}=$ cytochrome $\mathrm{c}$.

with enhanced electron dissipation and, thus, free radical formation $[17,18]$. In this context, it seems worth-while to look at the changes which naturally occur during aging in the absence of pharmacological treatments. As already outlined in the Introduction, rises in mitochondrial free-radical formation are observed during aging, which are related to impairments of electron flux and lead to electron dissipation. The causes for transient, local blockades of the ETC (Fig. 1) may be mainly sought in (i) more frequent interactions of elevated NO with irons in the ETC complexes; (ii) destructive actions of peroxynitrite-derived radicals, again a consequence of elevated NO; (iii) oxidative or nitrosative modifications at the major sites of electron leakage, i.e., (a) the especially vulnerable amphipathic ramp of Complex I and (b) Complex III, in which the interruption of the intramonomer electron transfer between the two $b_{\mathrm{L}}$ hemes at the Qo site seems to be decisive; (iv) cardiolipin peroxidation leading to dysfunction of Complexes III and IV; and (v) relative $\mathrm{O}_{2}$ deficiency that may result from atherosclerosis and which causes a secondary bottleneck of electron flux at Complex IV [17,18]. All these changes can occur concomitantly. A realistic picture of electron dissipation is only possible by considering its dynamics. Electron flux is by no means a steady and uniform homeostatic process occurring at more or less constant rates in a given metabolic situation. Recent investigations have shown that electron leakage happens in a flash-like fashion [139]. Therefore, bursts of superoxide anions, a source of $\mathrm{H}_{2} \mathrm{O}_{2^{-}}$and peroxynitritederived radicals, can be expected to be much stronger at reduced electron flux capacity, whereas basal rates should be less affected. The lesson from these considerations should be that maintenance of electron flux capacity is decisive for reducing electron dissipation and, thus, radical formation. With some likelihood, the management of radical avoidance by safeguarding electron flux may be much more efficient than the detoxification of radicals already formed $[17,18,58,91]$.

\section{MECHANISMS OF RADICAL AVOIDANCE AND POSSIBLE INTERVENTIONS}

Numerous causes of enhanced radical generation can be identified, also beyond toxicological and inflammationrelated effects. Already within the frame of physiological, lifestyle-dependent, genetically or age-related pathophysiological processes, elevated radical formation is possible. The chronobiological influence on oxidative damage has already been discussed. Correspondingly, the avoidance of unnecessary phase shifts and a chronohygiene in favor of sustained circadian amplitudes should be of advantage. The frequently observed age-related declines in SCN function and in nocturnal melatonin secretion may be seen as a possibility for interventions that could lead to reduced radical formation. Circadian amplitudes may be enhanced by repeated exposures to strong Zeitgeber signals, such as bright light in the morning, and/or melatonin, alternately other melatoninergic agonists, at fixed times in the evening. Additionally, these treatments favor appropriate circadian phasing relative to external time and, in the case of 
melatoninergic agonists, promote sleep onset in humans, which may be also of advantage for aged individuals [140]. As far as a substitution therapy is intended in cases of strongly reduced nocturnal melatonin, the natural hormone may be given daily, provided that no contraindications exist. If only enhancements of the circadian amplitude are required, melatonin or one of its synthetic analogs may be used for a few days, a procedure which should be repeated at intervals as individually required. In the relation to antioxidative protection, the use of melatonin instead of its analogs may be recommendable because of its additional beneficial effects, but this has to be distinguished from the chronobiotic actions concerning radical avoidance.

Reduced damage by free radicals is especially desirable in the central nervous system and may contribute to the

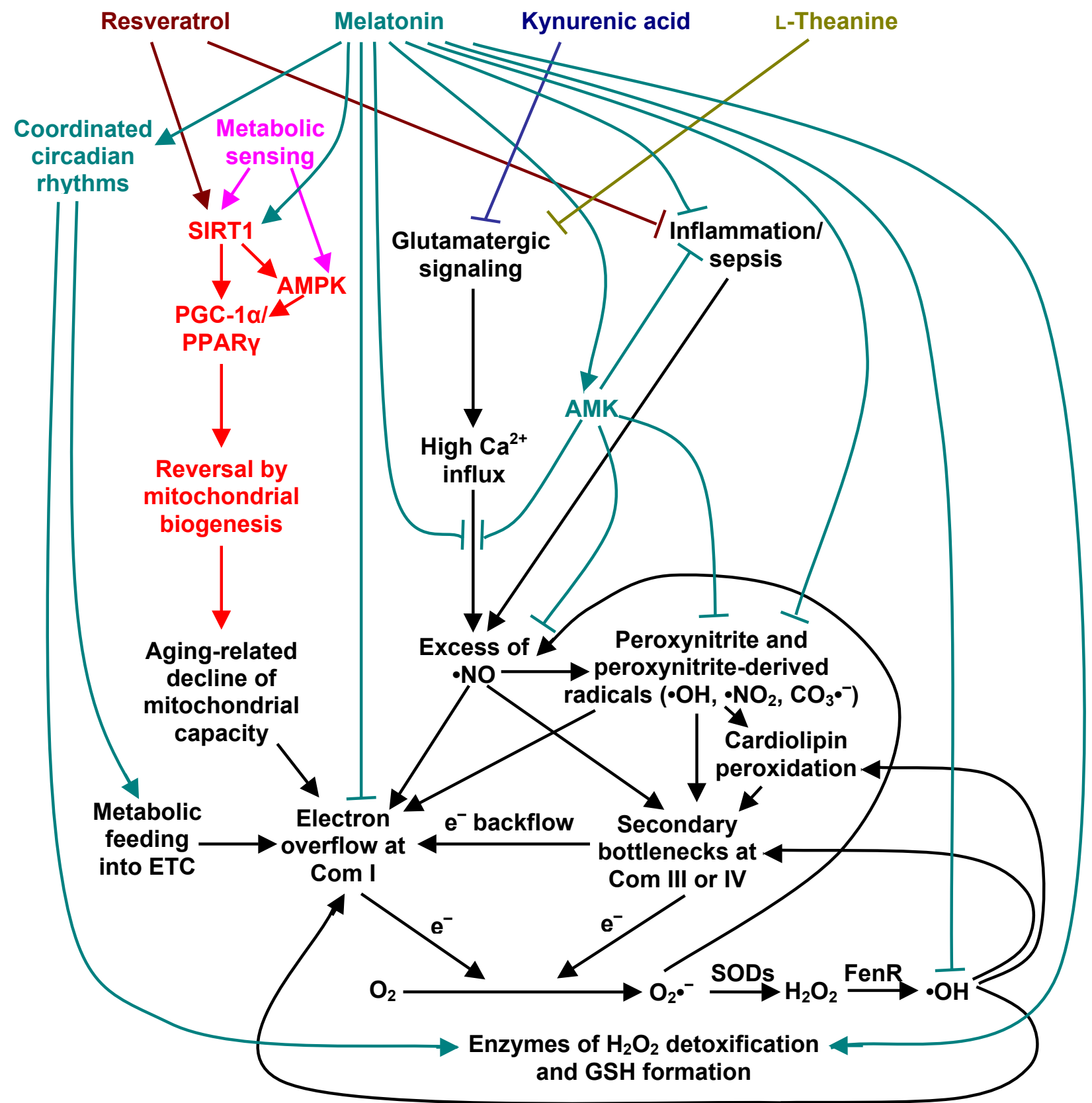

Fig. (2). Radical avoidance: multiple sites of intervention by several protective compounds. A simplified overview of a complex network. $\downarrow$ : Stimulation or chemical reaction; $\perp$ : inhibition. Colors of text and arrows, black: processes leading to enhanced formation of free radicals; brown: actions of resveratrol; green: actions of melatonin and its metabolite AMK; blue: main action of kynurenic acid; olive: main action of L-theanine; pink: responses to metabolic sensing; red: pathways influenced by multiple factors. Abbreviations: AMK $=N^{1}$-acetyl-5methoxykynuramine; AMPK = adenosine 5'-monophosphate-activated protein kinase; Com = complex (of respiratory chain); ETC = electron transport chain; FenR $=$ Fenton reaction; GSH = reduced glutathione; PGC-1 $\alpha=$ peroxisome proliferator-activated receptor- $\gamma$ coactivator-1 $\alpha$; PPAR $\gamma=$ peroxisome proliferator-activated receptor- $\gamma$; SIRT1 $=$ sirtuin-1; SODs $=$ superoxide dismutases. 
prevention or delay of neurodegeneration. In this context, the avoidance of neuronal overexcitation, in the worst case excitotoxicity, is of particular importance (Fig. 2). Longlasting neuronal excitation is usually associated with elevated calcium influx, leads to extended periods of high NO levels and, thus, peroxynitrite-induced damage. It may cause mitochondrial calcium overload, with the possible consequence of breakdown of the mitochondrial membrane potential and apoptosis. All these effects described are antagonized by melatonin [91,93,102-107]. Another compound highly efficient in suppressing neuronal overexcitation is kynurenic acid [141,142], which acts in multiple ways, by binding to the glycine ${ }_{B}$ site of the NMDA receptor $[143,144]$ and by decreasing extracellular glutamate levels by blocking presynaptic $\alpha 7$ nicotinic receptors ( $\alpha 7 \mathrm{nAChRs})$ at glutamatergic nerve endings [145,146]. An obstacle for the direct application of kynurenic acid is its poor penetration of the blood-brain barrier. However, this can be overcome by using indole-3-pyruvic acid, which is sufficiently taken up by the aromatic amino acid transporter and readily forms kynurenic acid via free-radical reactions [147-149]. In fact, administration of indole-3-pyruvic acid leads to rises in brain kynurenic acid [150]. The precursor has been clinically tested and was found to be suitable in reducing signs of chronic stress and mild anxiety, in accordance with the assumed anti-excitatory action of the product, kynurenic acid [151,152]. From the antagonism to overexcitation one might also deduce decreases in radical formation and, thus, a mitigation of oxidative stress.

While the above-mentioned mechanisms are widely related to intercellular signaling, direct effects on mitochondria may be expected to be even more effective in reducing radical formation. Again, melatonin is a compound of premier interest because of its actions as a mitochondrial metabolism modifier [58]. The indoleamine, previously mainly regarded as a radical scavenger and regulator of redox-active enzymes, exerts several additional actions at the mitochondrial level that exceed the earlier findings (Fig. 2). Due to its amphilicity melatonin easily crosses membranes, but is also water-soluble and, therefore, available in any compartment and in the lipid environment as well. Moreover, it has been shown to accumulate in mitochondria $[153,154]$. Again, melatonin acts in multiple ways, which collectively contribute to radical avoidance. First, melatonin interferes with NO metabolism by down-regulating the inducible nitric oxide synthase (iNOS), especially a mitochondrially targeted iNOS subform [154-159], by inhibiting neuronal NOS (nNOS) [107,160-164], scavenging of NO and peroxynitrite-derived radicals [89,107,165,166] (Fig. 3). Moreover, melatonin's metabolite, $N^{1}$-acetyl-5methoxykynuramine (AMK) acts as a potent scavenger of NO [167-170], of ROS formed from peroxynitrite [167], and as a highly efficient inhibitor of nNOS [171]. Therefore, any NO-related partial ETC blockade is antagonized by melatonin and its product. Second, melatonin supports the function of the ETC by preventing lipid peroxidation in mitochondrial membranes, in particular that of cardiolipin, which is crucial for the appropriate function of Complexes III and IV [17,18,112,172,173] (Fig. 2). Lipids, in particular, cardiolipin, are additionally protected by melatonin because of its influences on glutathione metabolism and the upregulation of mitochondrial glutathione peroxidase (GPx) [105-109,111,174-176]. This has been also demonstrated in SAMP8 mice, in which melatonin antagonized the agerelated decreases in GPx [99,109,111]. Although these studies did not specifically relate the effects observed to the isoform GPx4, this enzyme should have been involved. Moreover, cytochrome c release was shown to be strongly affected by GPx4 levels, and cardiolipin was protected in

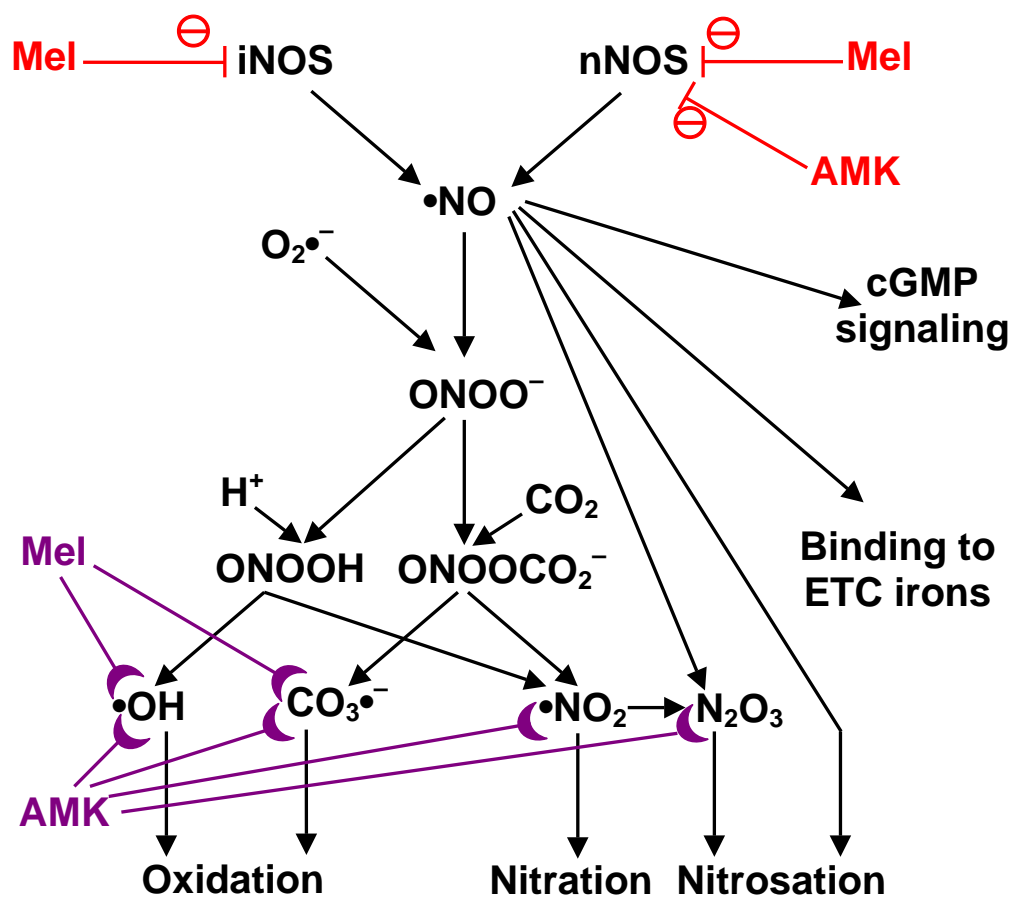

Fig. (3). Some aspects of NO metabolism, which are related to mitochondrial effects and counteractions by melatonin (Mel) and its metabolite $N^{1}$-acetyl-5-methoxykynuramine (AMK). Red arrows and symbols: down-regulation or inhibition; violet symbols: scavenging. 
transgenic mice overexpressing this isoenzyme, whereas, in heterozygous knockouts, cardiolipin peroxidation was exacerbated [177]. Third, melatonin modulates mitochondrial metabolism by directly interacting with the ETC $[17,18]$.

The direct effects of melatonin at the ETC have remained unclear for quite some time, and more specific data were obtained not before recently. One of the ideas for explaining the reduction in electron leakage caused by melatonin had been that of an electron shuttle, in which the indole acts as an electron donor to the ETC and the resulting melatonyl radical as an electron acceptor [58,91,93]. A corresponding action was assumed for AMK [58,91]. Electron donation to the ETC was, in fact, observed at cytochrome c, but the oxidation process studied led to AFMK, at least under the experimental conditions used [178]. Therefore, the idea of an electron shuttle bridging electron acceptor sites and those of electron dissipation would still require experimental support. However, this concept had not been entirely speculative, because it was designed on the basis of experience with nitrones [58]. These compounds are known as spin traps, but, compared to melatonin, they are relatively poor radical scavengers. Nevertheless, they are effective in supporting the electron flux through the ETC, thereby reducing oxidative stress [179-181], findings which may be interpreted in terms of decreased electron leakage and improved radical avoidance. Since the compound used in earlier studies, $\alpha$ phenyl-tert-butylnitrone $(\mathrm{PBN})$, had some unfavorable properties with regard to mitochondrial entrance and decomposition, derivatives were developed which were specifically designed for mitochondrial targeting, e.g., by making the compounds more amphiphilic [181-185]. Several of these newly developed nitrones were much more potent scavengers than PBN, but, more importantly, they protected from $\mathrm{H}_{2} \mathrm{O}_{2}$, peroxynitrite and doxorubicin toxicity with high efficiency [182-185]. In a gerontological model organism, the rotifer Philodina acuticornis odiosa, some of these compounds exerted remarkable effects of life extension. The amphiphilic nitrone LPBNAH was capable of more than doubling mean and maximal lifespan [182]. This effect was obviously not caused by slowing metabolic processes, as known from life-extending, ETC-related mutants of Caenorhabditis elegans [17,186,187], since the longer-lived rotifers grew to much larger sizes than the normal-lived animals [182]. Unfortunately, corresponding experiments in mice were not successful, presumably because of decomposition of these nitrones in the murine metabolism differing from that of rotifers, and formation of harmful products. However, the nitrone effects in Philodina may be taken as a proof of principle for the efficacy of mitochondrial metabolism modifiers.

The distinction between mitochondrial metabolism modification and free-radical scavenging seems to be of particular importance, although several of the protective compounds combine the two properties, foremost melatonin and its metabolite AMK. Experiments with L-theanine, a substance present in green tea leaves, but being almost devoid of radical scavenging properties, was found to efficiently prolong life in outbred mice not prematurely dying from cancer, in Fischer 344 rats and in Philodina. LTheanine also supported healthy aging of mice, restored brain ATP levels to normal in 24 months old rats, prevented neurodegeneration in the hippocampal areas CA1 and CA3 and restored the hippocampal density of serotoninergic innervation [B Poeggeler, pers commun]. These data by MA Pappolla and B Poeggeler, which are not yet published in detail, but were briefly cited elsewhere [132], could be related to the modification of mitochodrial metabolism in the central nervous system. The efficacy of the compound is obviously of indirect nature, due to the modulation of glutamatergic neurotransmission, and presumably includes the prevention of overexcitation [188] (Fig. 2).

The mitochondrial effects of melatonin may be partially independent of redox reactions. In addition to the previously known low-affinity binding site related to the inhibition of the mitochondrial permeability transition pore [189], a different, high-affinity mitochondrial binding site exists. Earlier studies in pigeon brain had shown that $39 \%$ of 2 iodomelatonin was bound to mitochondria [190]. More recently, the high-affinity site $\left(\mathrm{K}_{\mathrm{d}}=150 \mathrm{pM}\right)$ was found to be localized at the amphipathic ramp of Complex I and seems to be associated with melatonin-dependent rises in the activity of the iron-sulfur cluster N2 [17,18,96,132,134,191]. These data by MA Pappolla, B Poeggeler and B Pucci have not yet been published in detail, but some characteristics have been reported [191]. Displacement experiments with specific ligands indicated binding near the N2 cluster. These results strongly favor the idea that melatonin may directly control electron flux at Complex I and, thereby, reduce electron dissipation at this site, an action of radical avoidance.

\section{CONNECTIONS BETWEEN REDOX, SENSING MECHANISMS AND AGING-SUPPRESSOR GENES?}

The conclusion that anti-oxidative protection is much more than radical scavenging and regulation of anti- and prooxidant enzymes, but rather has to consider the attenuation of free-radical generation, necessarily leads to the question of how mitochondrial function is controlled and dysfunction avoided. This complex of problems remains to be elucidated in many details. Nevertheless, various indications for future studies exist. The processes of aging have been shown to be influenced by mechanisms of both redox and nutrient sensing [192]. Since nutrients are also related to the energy balance and, thus, mitochondrial function, interconnections between redox- and nutrient-regulated pathways have to be expected. Their terminal actions seem to control electron flux and dissipation, but also mitochondrial biogenesis.

Calorie restriction has been frequently used as a means for prolonging life [4,192-195]. Nutrient sensing had been related to the signaling pathway of growth hormone $(\mathrm{GH})$ and insulin-like growth factor-1 (IGF-1), whose disruption robustly favored longevity [193]. However, an additional relationship between caloric restriction and the aging suppressor SIRT1 became apparent $[4,193,194]$. Sirtuins are known to promote longevity in numerous organisms, from yeast to insects and vertebrates. The seven mammalian subforms, SIRT1 to SIRT7, are multiply involved in mitochondrial function. At least SIRT3, SIRT4 and SIRT5 are mitochondrially localized [196]. Like another aging suppressor, klotho, SIRT3 modulates the FoxO signaling pathway by interacting with the mitochondrial FoxO3a homolog, daf-16 [197]. Due to its function as an $\mathrm{NAD}^{+}$- 
dependent lysine deacetylase [198], SIRT3 prevents mitochondrial lysine hyperacetylation [196]. In fibroblasts, it was shown to physically interact with the Complex I subunit, the 39-kDa protein NDUFA9, to enhance Complex I activity and ATP levels [199]. The functional relationship of sirtuins to mitochondria goes beyond their presence within these organelles, comprises additional regulatory effects and also mitochondrial biogenesis [4] (Fig. 2). The subform SIRT1, which is not mitochondrially localized, also modulates NO formation, the insulin/IGF-1 pathway, activates FoxO subforms and, thereby, anti-oxidant enzyme expression $[4,200]$. A connection to free radical metabolism is, therefore, evident. The requirement of SIRT1 for mitochondrial activity becomes obvious by its dependence on the AMP level, an indicator of ATP deficiency. Normally, SIRT1 as well as AMP-activated protein kinase (AMPK) simultaneously respond to elevated AMP, but these two important regulators also act concordantly in situations of stress, starvation or calorie restriction [201] (Fig. 2). SIRT1 seems to have additional effects on mitochondrial electron transport capacity, including the amount of mitochondrial volume per cell $[4,200]$. Increased mitochondrial biogenesis was found to be associated with rises in AMPK, in NO - which, at moderate concentrations not leading to detrimental peroxynitrite levels, should not be generally harmful - and, more in particular, with the up-regulation of the peroxisome proliferator-activated receptor- $\gamma$ coactivator- $1 \alpha$ (PGC- $1 \alpha$ ) [202,203] (Fig. 2). A further connection exists with regard to circadian rhythmicity, which we had discussed in its relevance to radical avoidance. SIRT1 was shown to modulate chromatin remodeling via the clock gene protein CLK and seems to directly influence at least peripheral oscillators by interacting with the CLK/BMAL1 complex [204,205]. These actions should lead, for fundamental reasons, to numerous secondary effects, also beyond chromatin structure.

It seems that the relationships between mitochondrial regulators and the anti-oxidative defense are more complex than previously thought. AMPK was shown to be upregulated by peroxynitrite, so that the activation of this enzyme was concluded to represent an early warning signal of oxidative stress [206]. Resveratrol, which is, among other properties, a radical scavenger, anti-oxidant and anti-inflammatory agent [207-209], has also been identified as a dietary modulator and ligand of SIRT1 [4,210] (Fig. 2). Resveratrol, being the most potent natural SIRT1 activator [8], loses its chemopreventive efficacy in SIRT1 knockouts, so that the most potent pertinent actions are obviously mediated via this sirtuin isoform [211]. Stimulation of mitochondrial biogenesis via SIRT1 signaling involves PGC-1 $\alpha[193,195$, 212]. In endothelial cells, resveratrol increased mitochondrial mass and mtDNA content via SIRT1 and up-regulation of eNOS. Knockdown experiments showed that the blockade of either SIRT1 expression or NO formation prevented these effects [212]. Although the involvement of NO may be celltype specific, it demonstrates again that moderate levels of this gaseous mediator are not detrimental per se. Another anti-oxidant, $\alpha$-lipoic acid, also acts via PGC-1 $\alpha$ [203]. However, it remains to be clarified whether the protective effects of this compound are mainly exerted through this signaling pathway or through lipoylation of mitochondrial proteins, which is also required for the normal functioning of the ETC, especially Complex I [213]. With regard to mitochondrial actions of sirtuins and their common endpoints with mela-tonin, we had suggested to investigate their connection to the indoleamine [191]. Thereafter, first indications were obtained for such a relationship: in SAMP8 mice, melatonin was reported to up-regulate SIRT1 [214]. Recently, more detailed studies have supported the influence of melatonin on SIRT1. In a model using sleep-deprived rats [215], mela-tonin was shown to favor the hippocampal expression of SIRT1. In another investigation, neuronal cultures from young and aged rats were compared with regard to effects of melatonin [216]. In neurons from aged rats, melatonin up-regulated SIRT1 expression and also enhanced the deacety-lation of various SIRT1 substrates, such as PGC-1 $\alpha$, FoxO1, NFкB, and p53, effects which were largely reverted by the SIRT1 inhibitor sirtinol [216]. The melatonin-induced deacetylation of PGC- $1 \alpha$ indicates that mitochondrial biogenesis might be stimulated by the indoleamine in vivo.

\section{CONCLUSION}

Multiple connections exist between oxidative damage and aging. However, it seems important to avoid simplifications. Although the supply with anti-oxidants may favor a healthy aging, one should not expect to arrive at substantial extensions of lifespan by only detoxifying free-radicals and other oxidants formed, even not when this comprises upregulations of anti-oxidant enzymes. With regard to the crucial roles of mitochondria in the generation of free radicals and other oxidants, as well as in the aging-related metabolic decline, the support of mitochondrial function turns out to be of highest relevance. A well-operating ETC does not only provide sufficient amounts of ATP, but, at the same time, avoids electron dissipation and thereby radical formation. A compromised ETC may be regarded as a source of further damage and cellular decline, but this should not be interpreted in terms of the original version of the free radical theory of aging. If a vicious cycle exists, it is not that one between the radical producing ETC and the mtDNA, but rather another one within the ETC itself. Damage to the ETC causes oxidant formation, which leads to further impairment of electron flux. Radical avoidance as an aim of antioxidative protection intends to safeguard electron flux. Several low molecular weight molecules, such as resveratrol, $\alpha$-lipoic acid, melatonin and its metabolite AMK may be suitable for helping sustain the electron transport through the ETC and for reducing radical formation. Although these compounds have been regarded in the beginning mainly as direct anti-oxidants and, later, also as regulators of anti- and pro-oxidant enzymes, their role in the control of ETC components and mitochondrial biogenesis may be decisive. It remains fascinating to see evidence accumulating, which reveals how some of these chemically entirely different compounds merge at same pathways to promote mitochondrial growth. The earlier findings indicating an important role of the circadian oscillator system in avoiding oxidative damage now receives further support by the demonstration that PGC- $1 \alpha$, a central regulator of mitochondrial biogenesis, is, at the same time, involved in the circadian control. Melatonin, which does not only regulate anti- and pro-oxidant enzymes, combines properties of a 
major circadian regulator and a mitochondrial metabolism modifier. It may now be seen in this larger context of a regulatory network centered at the support of mitochondrial function.

\section{REFERENCES}

[1] Swain SL, Nikolich-Zugich J. Key research opportunities in immune system aging. J Gerontol A Biol Sci Med Sci 2009; 64: 183-6.

[2] Nomellini V, Gomez CR, Kovacs EJ. Aging and impairment of innate immunity. Contrib Microbiol 2008; 15: 188-205.

[3] Smith BC, Hallows WC, Denu JM. Mechanisms and molecular probes of sirtuins. Chem Biol 2008; 15: 1002-13.

[4] Guarente L. Mitochondria - a nexus for aging, calorie restriction, and sirtuins? Cell 2008; 132: 171-6.

[5] Bostock CV, Soiza RL, Whalley LJ. Genetic determinants of ageing processes and diseases in later life. Maturitas 2009; 62: 2259.

[6] Ljubuncic P, Reznick AZ. The evolutionary theories of aging revisited - a mini-review. Gerontology 2009; 55: 205-16.

[7] Shoba B, Lwin ZM, Ling LS, et al. Function of sirtuins in biological tissues. Anat Rec (Hoboken) 2009; 292: 536-43.

[8] Alcaín FJ, Villalba JM. Sirtuin activators. Expert Opin Ther Pat 2009; 19: 403-14.

[9] Kurosu H, Yamamoto M, Clark JD, et al. Suppression of aging in mice by the hormone Klotho. Science 2005; 309: 1829-33.

[10] Sato I, Miyado M, Sunohara M. NADH dehydrogenase activity and expression of mRNA of complex I (ND1, 51kDa, and 75kDa) in heart mitochondria of klotho mouse. Okajimas Folia Anat Jpn 2005; 82: 49-56.

[11] Haruna $\mathrm{Y}$, Kashihara N, Satoh M, et al. Amelioration of progressive renal injury by genetic manipulation of Klotho gene. Proc Natl Acad Sci USA 2007; 104: 2331-6.

[12] Sinha J, Chen F, Miloh T, et al. $\beta$-Klotho and FGF-15/19 inhibit the apical sodium-dependent bile acid transporter in enterocytes and cholangiocytes. Am J Physiol Gastrointest Liver Physiol 2008; 295: G996-1003.

[13] Kurosu H, Kuro-o M. The Klotho gene family and the endocrine fibroblast growth factors. Mol Cell Endocrinol 2009; 299: 72-8.

[14] Wang Y, Sun Z. Current understanding of klotho. Ageing Res Rev 2009; 8: 43-51.

[15] Blanchard B, Pompon D, Ducrocq C. Nitrosation of melatonin by nitric oxide and peroxynitrite. J Pineal Res 2000; 29: 184-92.

[16] Hardeland R, Poeggeler B, Niebergall R, Zelosko V. Oxidation of melatonin by carbonate radicals and chemiluminescence emitted during pyrrole ring cleavage. J Pineal Res 2003; 34: 17-25.

[17] Hardeland, R. Melatonin, mitochondrial electron flux and leakage: recent findings and resolution of contradictory results. Adv Stud Biol 2009; 1: 207-230.

[18] Hardeland R, Poeggeler B, Pappolla MA. Mitochondrial actions of melatonin - an endeavor to identify their adaptive and cytoprotective mechanisms. Abh Sächs Akad Wiss Math-Nat Kl, Endokrinologie Pt 4, 2009; 65: 14-31.

[19] Fannin SW, Lesnefsky EJ, Slabe TJ, et al. Aging selectively decreases oxidative capacity in rat heart interfibrillar mitochondria. Arch Biochem Biophys 1999; 372: 399-407.

[20] Lesnefsky EJ, Gudz TI, Moghaddas S, et al. Aging decreases electron transport complex III activity in heart interfibrillar mitochondria by alteration of the cytochrome $\mathrm{c}$ binding site. J Mol Cell Cardiol 2001; 33: 37-47.

[21] Hoppel CL, Moghaddas S, Lesnefsky EJ. Interfibrillar cardiac mitochondrial complex III defects in the aging rat heart. Biogerontology 2002; 3: 41-4.

[22] Moghaddas S, Stoll MS, Minkler PE, et al. Preservation of cardiolipin content during aging in rat heart interfibrillar mitochondria. J Gerontol A Biol Sci Med Sci 2002; 57: B22-8.

[23] Moghaddas S, Hoppel CL, Lesnefsky EJ. Aging defect at the Qo site of complex III augments oxyradical production in rat heart interfibrillar mitochondria. Arch Biochem Biophys 2003; 414: 5966.

[24] Lesnefsky EJ, He D, Moghaddas S, Hoppel CL. Reversal of mitochondrial defects before ischemia protects the aged heart. FASEB J 2006; 20: 1543-5.
[25] Lesnefsky EJ, Hoppel CL. Cardiolipin as an oxidative target in cardiac mitochondria in the aged rat. Biochim Biophys Acta 2008; 1777: 1020-7.

[26] Harman D. The biologic clock: the mitochondria? J Am Geriatr Soc 1972; 20: 145-7.

[27] Harman D. The free radical theory of aging. Antioxid Redox Signal 2003; 5: 557-61.

[28] Miquel J, de Juan E, Sevila I. Oxygen-induced mitochondrial damage and aging. EXS 1992; 62: 47-57.

[29] Poeggeler B. Melatonin, aging, and age-related diseases: perspectives for prevention, intervention, and therapy. Endocrine 2005; 27: 201-12.

[30] Gruber J, Schaffer S, Halliwell B. The mitochondrial free radical theory of ageing —where do we stand? Front Biosci 2008; 13: 6554-79.

[31] Poeggeler B, Reiter RJ, Tan DX, et al. Melatonin, hydroxyl radical-mediated oxidative damage, and aging: a hypothesis. J Pineal Res 1993; 14: 151-68.

[32] Sohal RS. The free radical hypothesis of aging: an appraisal of the current status. Aging (Milano) 1993; 5: 3-17.

[33] Shigenaga MK, Hagen TM, Ames BN. Oxidative damage and mitochondrial decay in aging. Proc Natl Acad Sci USA 1994; 91: 10771-8.

[34] Joseph JA, Denisova N, Fisher D, et al. Age-related neurodegeneration and oxidative stress: putative nutritional intervention. Neurol Clin 1998; 16: 747-55.

[35] Liu J, Mori A. Stress, aging, and brain oxidative damage. Neurochem Res 1999; 24: 1479-97.

[36] Skinner AM, Turker MS. Oxidative mutagenesis, mismatch repair, and aging. Sci Aging Knowl Environ 2005; 2005: article re3.

[37] Humphries KM, Szweda PA, Szweda LI. Aging: a shift from redox regulation to oxidative damage. Free Radic Res 2006; 40: 1239-43.

[38] Petropoulos I, Friguet B. Maintenance of proteins and aging: the role of oxidized protein repair. Free Radic Res 2006; 40: 1269-76.

[39] Chakravarti B, Chakravarti DN. Oxidative modification of proteins: age-related changes. Gerontology 2007; 53: 128-39.

[40] Gilca M, Stoian I, Atanasiu V, Virgolici B. The oxidative hypothesis of senescence. J Postgrad Med 2007; 53: 207-13.

[41] Giorgio M, Trinei M, Migliaccio E, Pelicci PG. Hydrogen peroxide: a metabolic by-product or a common mediator of ageing signals? Nat Rev Mol Cell Biol 2007; 8: 722-8.

[42] Chen JH, Hales CN, Ozanne SE. DNA damage, cellular senescence and organismal ageing: causal or correlative? Nucleic Acids Res 2007; 35: 7417-28

[43] Martien S, Abbadie C. Acquisition of oxidative DNA damage during senescence: the first step toward carcinogenesis? Ann NY Acad Sci 2007; 1119: 51-63.

[44] Figueiredo PA, Mota MP, Appell HJ, Duarte JA. The role of mitochondria in aging of skeletal muscle. Biogerontology 2008; 9 : 67-84.

[45] Pang CY, Ma YS, Wei YU. MtDNA mutations, functional decline and turnover of mitochondria in aging. Front Biosci 2008; 13: 3661-75.

[46] Pamplona R. Membrane phospholipids, lipoxidative damage and molecular integrity: a causal role in aging and longevity. Biochim Biophys Acta 2008; 1777: 1249-62.

[47] Khansari N, Shakiba Y, Mahmoudi M. Chronic inflammation and oxidative stress as a major cause of age-related diseases and cancer. Recent Pat Inflamm Allergy Drug Discov 2009; 3: 73-80.

[48] Limón-Pacheco J, Gonsebatt ME. The role of antioxidants and antioxidant-related enzymes in protective responses to environmentally induced oxidative stress. Mutat Res 2009; 674: 137-47.

[49] Ames BN, Shigenaga MK, Hagen TM. Mitochondrial decay in aging. Biochim Biophys Acta 1995; 1271: 165-70.

[50] Mori A, Utsumi K, Liu J, Hosokawa M. Oxidative damage in the senescence-accelerated mouse. Ann NY Acad Sci 1998; 854: 23950 .

[51] Fukui H, Moraes CT. The mitochondrial impairment, oxidative stress and neurodegeneration connection: reality or just an attractive hypothesis? Trends Neurosci 2008; 31: 251-6.

[52] Thompson LV. Oxidative stress, mitochondria and mtDNAmutator mice. Exp Gerontol 2006; 41: 1220-2.

[53] Kanki T, Nakayama H, Sasaki N, et al. Mitochondrial nucleoid and transcription factor A. Ann NY Acad Sci 2004; 1011: 61-8. 
[54] Ekstrand MI, Falkenberg M, Rantanen A, et al. Mitochondrial transcription factor A regulates mtDNA copy number in mammals. Hum Mol Genet 2004; 13: 935-44.

[55] Kang D, Hamasaki N. Mitochondrial transcription factor A in the maintenance of mitochondrial DNA: overview of its multiple roles. Ann NY Acad Sci 2005; 1042: 101-8.

[56] Kienhöfer J, Häussler DJ, Ruckelshausen F, et al. Association of mitochondrial antioxidant enzymes with mitochondrial DNA as integral nucleoid constituents. FASEB J 2009; 23: 2034-44.

[57] Hurd MW, Ralph MR. The significance of circadian organization for longevity in the golden hamster. J Biol Rhythms 1998; 13: 4306.

[58] Hardeland R, Coto-Montes A, Poeggeler B. Circadian rhythms, oxidative stress, and antioxidative defense mechanisms. Chronobiol Int 2003; 20: 921-62.

[59] Coto-Montes A, Hardeland R. Diurnal rhythm of protein carbonyl as an indicator of oxidative damage in Drosophila melanogaster: Influence of clock gene alleles and deficiencies in the formation of free-radical scavengers. Biol Rhythm Res 1999; 30: 383-91.

[60] Krishnan N, Davis AJ, Giebultowicz JM. Circadian regulation of response to oxidative stress in Drosophila melanogaster. Biochem Biophys Res Commun 2008; 374: 299-303.

[61] Coto-Montes A, Tomás-Zapico C, Rodríguez-Colunga MJ, et al. Effects of the circadian mutation 'tau' on the Harderian glands of Syrian hamsters. J Cell Biochem 2001; 83: 426-34.

[62] Coto-Montes A, Boga JA, Tomás-Zapico C, et al. Physiological oxidative stress model: Syrian hamster Harderian gland - Sex differences in antioxidant enzymes. Free Radic Biol Med 2001; 30: 785-92.

[63] Aschoff J, v. Saint Paul U, Wever R. Die Lebensdauer von Fliegen unter dem Einfluß von Zeit-Verschiebungen. Naturwissenschaften 1971; 58: 574

[64] Penev PD, Kolker DE, Zee PC, Turek FW. Chronic circadian desynchronization decreases the survival of animals with cardiomyopathic heart disease. Am J Physiol 1998; 275: H2334-7.

[65] Nakamura K, Shimai S, Kikuchi S, et al. Shift work and risk factors for coronary heart disease in Japanese blue-collar workers: serum lipids and anthropometric characteristics. Occup Med (Lond) 1997; 47: 142-6.

[66] Schernhammer ES, Laden F, Speizer FE, et al. Night-shift work and risk of colorectal cancer in the nurses' health study. J Natl Cancer Inst 2003; 95: 825-8.

[67] Stevens RG. Circadian disruption and breast cancer: from melatonin to clock genes. Epidemiology 2005; 16: 254-8.

[68] Haus E, Smolensky M. Biological clocks and shift work: circadian dysregulation and potential long-term effects. Cancer Causes Control 2006; 17: 489-500.

[69] Moser M, Penter R, Fruehwirth M, Kenner T. Why life oscillates - biological rhythms and health. Conf Proc IEEE Eng Med Biol Soc 2006; 1: 424-8.

[70] Brown DL, Feskanich D, Sánchez BN, et al. Rotating night shift work and the risk of ischemic stroke. Am J Epidemiol 2009; 169: 1370-7.

[71] Fu L, Pelicano H, Liu J, et al. The circadian gene period2 plays an important role in tumor suppression and DNA damage response in vivo. Cell 2002; 111: 41-50.

[72] Rosbach M, Takahashi JS. Circadian rhythms: The cancer connection. Nature 2002; 420: 373-4.

[73] Chen ST, Choo KB, Hou MF, et al. Deregulated expression of the PER1, PER2 and PER3 genes in breast cancers. Carcinogenesis 2005; 26: 1241-6.

[74] Gery S, Komatsu N, Baldjyan L, et al. The circadian gene per1 plays an important role in cell growth and DNA damage control in human cancer cells. Mol Cell 2006; 22: 375-82.

[75] Gery S, Komatsu N, Kawamata N, et al. Epigenetic silencing of the candidate tumor suppressor gene Per1 in non-small cell lung cancer. Clin Cancer Res 2007; 13: 1399-404.

[76] Gery S, Koeffler HP. The role of circadian regulation in cancer. Cold Spring Harb Symp Quant Biol 2007; 72: 459-64.

[77] Chen-Goodspeed M, Lee CC. Tumor suppression and circadian function. J Biol Rhythms 2007; 22: 291-8.

[78] Tokunaga $\mathrm{H}$, Takebayashi $\mathrm{Y}$, Utsunomiya $\mathrm{H}$, et al. Clinicopathological significance of circadian rhythm-related gene expression levels in patients with epithelial ovarian cancer. Acta Obstet Gynecol Scand 2008; 87: 1060-70.
[79] Lin YM, Chang JH, Yeh KT, et al. Disturbance of circadian gene expression in hepatocellular carcinoma. Mol Carcinog 2008; 47: 925-33.

[80] Wood PA, Yang X, Taber A, et al. Period 2 mutation accelerates $\mathrm{Apc}^{\mathrm{Min} /+}$ tumorigenesis. Mol Cancer Res 2008; 6: 1786-93.

[81] Korkmaz A, Sanchez-Barcelo EJ, Tan D-X, Reiter RJ. Role of melatonin in the epigenetic regulation of breast cancer. Breast Cancer Res Treat 2009; 115: 13-27.

[82] Yang X, Wood PA, Ansell CM, et al. $\beta$-Catenin induces $\beta$-TrCPmediated PER2 degradation altering circadian clock gene expression in intestinal mucosa of $\mathrm{Apc}^{\mathrm{Min} /+}$ mice. J Biochem 2009; 145: 289-97.

[83] Shih MC, Yeh KT, Tang KP, et al. Promoter methylation in circadian genes of endometrial cancers detected by methylationspecific PCR. Mol Carcinog 2006; 45: 732-40.

[84] Kuo SJ, Chen ST, Yeh KT, et al. Disturbance of circadian gene expression in breast cancer. Virchows Arch 2009; 454: 467-74.

[85] Tan D-X, Manchester LC, Hardeland R, et al. Melatonin - a hormone, a tissue factor, an autocoid, a paracoid, and an antioxidant vitamin. J Pineal Res 2003; 34: 75-8.

[86] Tan D-X, Chen L-D, Poeggeler B, et al. Melatonin: a potent, endogenous hydroxyl radical scavenger. Endocr J 1993; 1: 57-60

[87] Tan D-X, Manchester LC, Reiter RJ, et al. Significance of melatonin in antioxidative defense system: reactions and products. Biol Signals Recept 2000; 9: 137-59.

[88] Tan D-X, Reiter RJ, Manchester LC, et al. Chemical and physical properties and potential mechanisms: melatonin as a broad spectrum antioxidant and free radical scavenger. Curr Top Med Chem 2002; 2: 181-97.

[89] Reiter RJ, Tan D-X, Mayo JC, et al. Melatonin as an antioxidant: biochemical mechanisms and pathophysiological implications in humans. Acta Biochim Pol 2003; 50: 1129-46.

[90] Rodriguez C, Mayo JC, Sainz RM, et al. Regulation of antioxidant enzymes: a significant role for melatonin. J Pineal Res 2004; 36: 19.

[91] Hardeland R. Antioxidative protection by melatonin: multiplicity of mechanisms from radical detoxification to radical avoidance. Endocrine 2005; 27: 119-30.

[92] Hardeland R, Pandi-Perumal SR. Melatonin, a potent agent in antioxidative defense: Actions as a natural food constituent, gastrointestinal factor, drug and prodrug. Nutr Metab (London). 2005 Sept 10. 2: article no 22 [15 screens]. Available from: http://www.biomedcentral.com/1743-7075/2/22

[93] Pandi-Perumal SR, Srinivasan V, Maestroni GJM, et al. Melatonin - Nature's most versatile biological signal? FEBS J 2006; 273: 2813-38.

[94] Reiter RJ, Tan D-X, Jou MJ, et al. Biogenic amines in the reduction of oxidative stress: melatonin and its metabolites. Neuroendocrinol Lett 2008; 29: 391-8.

[95] Korkmaz A, Reiter RJ, Topal T, et al. Melatonin: an established antioxidant worthy of use in clinical trials. Mol Med 2009; 15: 4350 .

[96] Hardeland R, Poeggeler B. Melatonin beyond its classical functions. Open Physiol J 2008; 1: 1-23.

[97] Acuña-Castroviejo D, Escames G, Carazo A, et al. Melatonin, mitochondrial homeostasis and mitochondrial-related diseases. Curr Top Med Chem 2002; 2: 133-51.

[98] Martín M, Macías M, León J, et al. Melatonin increases the activity of the oxidative phosphorylation enzymes and the production of ATP in rat brain and liver mitochondria. Int $\mathrm{J}$ Biochem Cell Biol 2002; 34: 348-57.

[99] Okatani Y, Wakatsuki A, Reiter RJ. Melatonin protects hepatic mitochondrial respiratory chain activity in senescence-accelerated mice. J Pineal Res 2002; 32: 143-8.

[100] Okatani Y, Wakatsuki A, Reiter RJ, Miyahara Y. Hepatic mitochondrial dysfunction in senescence-accelerated mice: correction by long-term, orally administered physiological levels of melatonin. J Pineal Res 2002; 33: 127-33.

[101] Okatani Y, Wakatsuki A, Reiter RJ, Miyahara Y. Acutely administered melatonin restores hepatic mitochondrial physiology in old mice. Int J Biochem Cell Biol 2003; 35: 367-75.

[102] Acuña-Castroviejo D, Escames G, León J, et al. Mitochondrial regulation by melatonin and its metabolites. Adv Exp Med Biol 2003; 527: 549-57.

[103] León J, Acuña-Castroviejo D, Escames G, et al. Melatonin mitigates mitochondrial malfunction. J Pineal Res 2005; 38: 1-9. 
[104] Leon J, Acuña-Castroviejo D, Sainz RM, et al. Melatonin and mitochondrial function. Life Sci 2004; 75: 765-90.

[105] Acuña-Castroviejo D, Escames G, Rodríguez MI, López LC. Melatonin role in the mitochondrial function. Front Biosci 2007; 12: 947-63.

[106] Reiter RJ, Tan DX, Manchester LC, El-Sawi MR. Melatonin reduces oxidant damage and promotes mitochondrial respiration: implications for aging. Ann NY Acad Sci 2002; 959: 238-50.

[107] Reiter RJ, Tan DX, Burkhardt S. Reactive oxygen and nitrogen species and cellular and organismal decline: amelioration with melatonin. Mech Ageing Dev 2002; 123: 1007-19.

[108] Rodríguez MI, Carretero M, Escames G, et al. Chronic melatonin treatment prevents age-dependent cardiac mitochondrial dysfunction in senescence-accelerated mice. Free Radic Res 2007; 41: 15-24.

[109] Rodriguez MI, Escames G, López LC, et al. Melatonin administration prevents cardiac and diaphragmatic mitochondrial oxidative damage in senescence-accelerated mice. $J$ Endocrinol 2007; 194: 637-43.

[110] Camello-Almaraz C, Gomez-Pinilla PJ, Pozo MJ, Camello PJ. Age-related alterations in $\mathrm{Ca}^{2+}$ signals and mitochondrial membrane potential in exocrine cells are prevented by melatonin. $\mathbf{J}$ Pineal Res 2008; 45: 191-8.

[111] Rodríguez MI, Escames G, López LC, et al. Improved mitochondrial function and increased life span after chronic melatonin treatment in senescent prone mice. Exp Gerontol 2008; 43: 749-56.

[112] Petrosillo G, Fattoretti P, Matera M, et al. Melatonin prevents agerelated mitochondrial dysfunction in rat brain via cardiolipin protection. Rejuvenation Res 2008; 11: 935-43.

[113] Touitou Y, Fèvre M, Lagugvey M, et al. Age and mental health related circadian rhythms of plasma levels of melatonin, prolactin, luteinizing hormone and follicle stimulating hormone. J Endocrinol 1981; 91: 467-75.

[114] Iguchi H, Kato KI, Ibayashi H. Age-dependent reduction is serum melatonin concentrations in healthy human subjects. J Clin Endocrinol Metab 1982; 55: 19-27.

[115] Nair NPV, Haribarasubramanian N, Pilapil C, et al. Plasma melatonin - An index of brain aging in humans? Biol Psychiatry 1986; 21: 141-50.

[116] Reiter RJ. The ageing pineal gland and its physiological consequences. Bioessays 1992; 14: 169-75.

[117] Sack RL, Lewy AJ, Erb DL, et al. Human melatonin production decreases with age. J Pineal Res 1986; 3: 379-88.

[118] Zhou JN, Liu RY, van Heerikhuize J, et al. Alterations in the circadian rhythm of salivary melatonin begin during middle-age. $\mathrm{J}$ Pineal Res 2003; 34: 11-6.

[119] Karasek M. Melatonin, human aging, and age-related diseases. Exp Gerontol 2004; 39: 1723-9.

[120] Münch M, Knoblauch V, Blatter K, et al. Age-related attenuation of the evening circadian arousal signal in humans. Neurobiol Aging 2005; 26: 1307-19.

[121] Mahlberg R, Tilmann A, Salewski L, Kunz D. Normative data on the daily profile of urinary 6-sulfatoxymelatonin in healthy subjects between the ages of 20 and 84. Psychoneuroendocrinology 2006; 31: 634-41.

[122] Karasek M. Does melatonin play a role in aging processes? J Physiol Pharmacol 2007; 58(Suppl 6): 105-13.

[123] Reiter RJ, Paredes SD, Korkmaz A, et al. Melatonin in relation to the "strong" and "weak" versions of the free radical theory of aging. Adv Med Sci 2008; 53: 119-29.

[124] Armstrong SM, Redman JR. Melatonin: A chronobiotic with antiaging properties. Med Hypotheses 1991; 34: 300-9.

[125] Van Remmen H, Ikeno Y, Hamilton M, et al. Life-long reduction in MnSOD activity results in increased DNA damage and higher incidence of cancer but does not accelerate aging. Physiol Genomics 2003; 16: 29-37.

[126] Mansouri A, Muller FL, Liu Y, et al. Alterations in mitochondrial function, hydrogen peroxide release and oxidative damage in mouse hind-limb skeletal muscle during aging. Mech Ageing Dev 2006; 127: 298-306.

[127] Sentman ML, Granström M, Jakobson H, et al. Phenotypes of mice lacking extracellular superoxide dismutase and copper- and zinccontaining superoxide dismutase. J Biol Chem 2006; 281: 6904-9.
[128] Jang YC, Van Remmen H. The mitochondrial theory of aging: insight from transgenic and knockout mouse models. Exp Gerontol 2009; 44: 256-60.

[129] Ungvari Z, Krasnikov BF, Csiszar A, et al. Testing hypotheses of aging in long-lived mice of the genus Peromyscus: association between longevity and mitochondrial stress resistance, ROS detoxification pathways, and DNA repair efficiency. Age (Dordr) 2008; 30: 121-33.

[130] Ungvari Z, Buffenstein R, Austad SN, et al. Oxidative stress in vascular senescence: lessons from successfully aging species. Front Biosci 2008; 13: 5056-70.

[131] Spindler SR, Mote PL. Screening candidate longevity therapeutics using gene-expression arrays. Gerontology 2007; 53: 306-21.

[132] Hardeland R, Poeggeler B. Actions of melatonin, its structural and functional analogs in the central nervous system and the significance of metabolism. Cent Nerv Syst Agents Med Chem 2007; 7: 289-303.

[133] Pearson KJ, Baur JA, Lewis KN, et al. Resveratrol delays agerelated deterioration and mimics transcriptional aspects of dietary restriction without extending life span. Cell Metab 2008; 8: 157-68.

[134] Hardeland R. Melatonin, hormone of darkness and more: occurrence, control mechanisms, actions and bioactive metabolites. Cell Mol Life Sci 2008; 65: 2001-18.

[135] Tomobe K, Nomura Y. Neurochemistry, neuropathology, and heredity in SAMP8: a mouse model of senescence. Neurochem Res 2009; 34:660-9.

[136] Cao H, Hegele RA. LMNA is mutated in Hutchinson-Gilford progeria (MIM 176670) but not in Wiedemann-Rautenstrauch progeroid syndrome (MIM 264090). J Hum Genet 2003; 48: 271-4.

[137] Brune T, Bonne G, Denecke J, et al. Progeria: a new kind of Laminopathy-report of the First European Symposium on Progeria and creation of EURO-Progeria, a European Consortium on Progeria and related disorders. Pediatr Endocrinol Rev 2004; 2:39-45.

[138] Zhang Q, Ding H, Li W, et al. Senescence accelerated mouse strain is sensitive to neurodegeneration induced by mild impairment of oxidative metabolism. Brain Res 2009; 1264: 111-8.

[139] Wang W, Fang H, Groom L, et al. Superoxide flashes in single mitochondria. Cell 2008; 134: 279-90.

[140] Hardeland R. New approaches in the management of insomnia: weighing the advantages of prolonged release melatonin and synthetic melatoninergic agonists. Neuropsychiatr Dis Treat 2009; 5: 341-54.

[141] Schwarcz R. The kynurenine pathway of tryptophan degradation as a drug target. Curr Opin Pharmacol 2004; 4: 12-7.

[142] Poeggeler B, Rassoulpour A, Wu HQ, et al. Dopamine receptor activation reveals a novel, kynurenate-sensitive component of striatal N-methyl-D-aspartate neurotoxicity. Neuroscience 2007; 148: 188-97.

[143] Kessler M, Terramani T, Lynch G, Baudry M. A glycine site associated with N-methyl-D-aspartic acid receptors: characterization and identification of a new class of antagonists. J Neurochem 1989; 52: 1319-28.

[144] Parsons CG, Danysz W, Quack G, et al. Novel systemically active antagonists of the glycine site of the N-methyl-D-aspartate receptor: electrophysiological, biochemical and behavioral characterization. J Pharmacol Exp Ther 1997; 283: 1264-75.

[145] Carpenedo R, Pittaluga A, Cozzi A, et al. Presynaptic kynurenatesensitive receptors inhibit glutamate release. Eur J Neurosci 2001; 13: 2141-7.

[146] Rassoulpour A, Wu HQ, Ferré S, Schwarcz R. Nanomolar concentrations of kynurenic acid reduce extracellular dopamine levels in the striatum. J Neurochem 2005; 93: 76-5.

[147] Politi V, Lavaggi MV, Di Stazio G, Margonelli A. Indole-3pyruvic acid as a direct precursor of kynurenic acid. In: Schwarcz R, Young SN, Brown RR, Eds. Kynurenine and serotonin pathways. Progress in tryptophan research. New York, Plenum Press 1991; pp. 515-8.

[148] Politi V, D’Alessio S, Di Stazio G, De Luca G. Antioxidant properties of indole-3-pyruvic acid. Adv Exp Med Biol 1996; 398: 291-298.

[149] Zsizsik BK, Hardeland R. Formation of kynurenic and xanthurenic acids from kynurenine and 3-hydroxykynurenine in the dinoflagellate Lingulodinium polyedrum: role of a novel, oxidative pathway. Comp Biochem Physiol C Toxicol Pharmacol 2002; 133: 383-92. 
[150] Russi P, Carlà V, Moroni F. Indolepyruvic acid administration increases the brain content of kynurenic acid. Is this a new avenue to modulate excitatory amino acid receptors in vivo? Biochem Pharmacol 1989; 38: 2405-9.

[151] Politi V, De Luca G, Gallai V, et al. Clinical experiences with the use of indole-3-pyruvic acid. Adv Exp Med Biol 1999; 467: 22732.

[152] Bartolini B, Corniello C, Sella A, et al. The enol tautomer of indole-3-pyruvic acid as a biological switch in stress responses. Adv Exp Med Biol 2003; 527: 601-8.

[153] Messner M, Hardeland R, Rodenbeck A, Huether G. Tissue retention and subcellular distribution of continuously infused melatonin in rats under near physiological conditions. J Pineal Res 1998; 25: 251-9.

[154] López A, García JA, Escames G, et al. Melatonin protects the mitochondria from oxidative damage reducing oxygen consumption, membrane potential, and superoxide anion production. J Pineal Res 2009; 46: 188-98.

[155] Escames G, Acuña-Castroviejo D, López LC, et al. Pharmacological utility of melatonin in the treatment of septic shock: experimental and clinical evidence. J Pharm Pharmacol 2006; 58: 1153-65.

[156] Escames G, López LC, Ortiz F, et al. Attenuation of cardiac mitochondrial dysfunction by melatonin in septic mice. FEBS J 2007; 274: 2135-47.

[157] Escames G., López LC, Tapias V, et al. Melatonin counteracts inducible mitochondrial nitric oxide synthase-dependent mitochondrial dysfunction in skeletal muscle of septic mice. J Pineal Res 2006; 40: 71-8.

[158] López LC, Escames G, Ortiz F, et al. Melatonin restores the mitochondrial production of ATP in septic mice. Neuroendocrinol Lett 2006; 27: 623-30.

[159] López LC, Escames G, Tapias V, et al. Identification of an inducible nitric oxide synthase in diaphragm mitochondria from septic mice: its relation with mitochondrial dysfunction and prevention by melatonin. Int J Biochem Cell Biol 2006; 38: 267-78.

[160] León J, Vives F, Crespo E, et al. Modification of nitric oxide synthase activity and neuronal response in rat striatum by melatonin and kynurenine derivatives. J Neuroendocrinol 1998; 10: 297-302.

[161] León J, Macías M, Escames G, et al. Structure-related inhibition of calmodulin-dependent neuronal nitric-oxide synthase activity by melatonin and synthetic kynurenines. Mol Pharmacol 2000; 58: 967-75.

[162] Chang HM, Ling EA, Chen CF, et al. Melatonin attenuates the neuronal NADPH-d/NOS expression in the nodose ganglion of acute hypoxic rats. J Pineal Res 2002; 32: 65-73.

[163] Chang HM, Tseng CY, Wei IH, et al. Melatonin restores the cytochrome oxidase reactivity in the nodose ganglia of acute hypoxic rats. J Pineal Res 2005; 39: 206-14.

[164] Tjong YW, Li MF, Hung MW, Fung ML. Melatonin ameliorates hippocampal nitric oxide production and large conductance calcium-activated potassium channel activity in chronic intermittent hypoxia. J Pineal Res 2008; 44: 234-43.

[165] Reiter RJ, Tan D-X, Manchester LC, Qi W. Biochemical reactivity of melatonin with reactive oxygen and nitrogen species: a review of the evidence. Cell Biochem Biophys 2001; 34: 237-56.

[166] Reiter RJ, Tan D-X, Manchester LC, et al. Melatonin: detoxification of oxygen and nitrogen-based toxic reactants. Adv Exp Med Biol 2003; 527: 539-48.

[167] Guenther AL, Schmidt SI, Laatsch H, et al. Reactions of the melatonin metabolite AMK ( $N^{1}$-acetyl-5-methoxykynuramine) with reactive nitrogen species: formation of novel compounds, 3acetamidomethyl-6-methoxycinnolinone and 3-nitro-AMK. J Pineal Res 2005; 39: 251-60.

[168] Hardeland R, Backhaus C, Fadavi A, Hess M. $N^{1}$-acetyl-5methoxykynuramine contrasts with other tryptophan metabolites by a peculiar type of NO scavenging: cyclization to a cinnolinone prevents formation of unstable nitrosamines. J Pineal Res 2007; 43: 104-5.

[169] Hardeland R, Backhaus C, Fadavi A. Reactions of the NO redox forms $\mathrm{NO}^{+}, \cdot \mathrm{NO}$ and $\mathrm{HNO}$ (protonated $\mathrm{NO}^{-}$) with the melatonin metabolite $N^{1}$-acetyl-5-methoxykynuramine. J Pineal Res 2007; 43: 382-8.
[170] Hardeland R, Tan D-X, Reiter RJ. Kynuramines, metabolites of melatonin and other indoles: the resurrection of an almost forgotten class of biogenic amines. J Pineal Res 2009; 47: 109-26.

[171] León J, Escames G, Rodríguez MI, et al. Inhibition of neuronal nitric oxide synthase activity by $N^{1}$-acetyl-5-methoxykynuramine, a brain metabolite of melatonin. J Neurochem 2006; 98: 2023-33.

[172] Petrosillo G, Di Venosa N, Pistolese M, et al. Protective effect of melatonin against mitochondrial dysfunction associated with cardiac ischemia-reperfusion: role of cardiolipin. FASEB J 2006; 20: 269-76.

[173] Luchetti F, Canonico B, Mannello F, et al. Melatonin reduces early changes in intramitochondrial cardiolipin during apoptosis in U937 cell line. Toxicol in vitro 2007; 21: 293-301.

[174] Wakatsuki A, Okatani Y, Shinohara K, et al. Melatonin protects fetal rat brain against oxidative mitochondrial damage. J Pineal Res 2001; 30: 22-8.

[175] Reiter RJ, Acuña-Castroviejo D, Tan DX, Burkhardt S. Free radical-mediated molecular damage. Mechanisms for the protective actions of melatonin in the central nervous system. Ann N Y Acad Sci 2001; 939: 200-15.

[176] Okatani Y, Wakatsuki A, Reiter RJ, et al. Protective effect of melatonin against mitochondrial injury induced by ischemia and reperfusion of rat liver. Eur J Pharmacol 2003; 469: 145-52.

[177] Liang H, Ran Q, Jang YC, et al. Glutathione peroxidase 4 differentially regulates the release of apoptogenic proteins from mitochondria. Free Radic Biol Med 2009; 47: 312-20.

[178] Semak I, Naumova M, Korik E, et al. A novel metabolic pathway of melatonin: oxidation by cytochrome C. Biochemistry 2005; 44 : 9300-7.

[179] Floyd RA. Nitrones as therapeutics in age-related diseases. Aging Cell 2006; 5: 51-7.

[180] Floyd RA, Kopke RD, Choi CH, et al. Nitrones as therapeutics. Free Radic Biol Med 2008; 45: 1361-74.

[181] El Fangour S, Marini M, Good J, et al. Nitrones for understanding and ameliorating the oxidative stress associated with aging. Age (Dordr) 2009; 31: 269-76.

[182] Poeggeler B, Durand G, Polidori A, et al. Mitochondrial medicine: neuroprotection and life extension by the new amphiphilic nitrone LPBNAH acting as a highly potent advanced antioxidant agent. J Neurochem 2005; 95: 962-73.

[183] Ortial S, Durand G, Poeggeler B, et al. Fluorinated amphiphilic amino acid derivatives as antioxidant carriers: a new class of protective agents. J Med Chem 2006; 49: 2812-20.

[184] Durand G, Poeggeler B, Böker J, et al. Fine-tuning the amphiphilicity: a crucial parameter in the design of potent $\alpha$ phenyl-N-tert-butylnitrone analogues. J Med Chem 2007; 50: 3976-9.

[185] Durand G, Poeggeler B, Ortial S, et al. Amphiphilic nitrone amines: a new class of protective agents acting as mitochondrial metabolism modifiers. Free Radic Biol Med 2007; 43: S91-2.

[186] Braeckman BP, Houthoofd K, Brys K, et al. No reduction of energy metabolism in Clk mutants. Mech Ageing Dev 2002; 123: 1447-56.

[187] Kayser E-B, Sedensky MM, Morgan PG. The effects of complex I function and oxidative damage on lifespan and anesthetic sensitivity in Caenorhabditis elegans. Mech Ageing Dev 2004. 125: 455-64.

[188] Nathan PJ, Lu K, Gray M, Oliver C. The neuropharmacology of Ltheanine ( $N$-ethyl-L-glutamine): a possible neuroprotective and cognitive enhancing agent. J Herb Pharmacother 2006; 6: 21-30.

[189] Andrabi SA, Sayeed I, Siemen D, et al. Direct inhibition of the mitochondrial permeability transition pore: a possible mechanism responsible for anti-apoptotic effects of melatonin. FASEB J 2004; 18: 869-71.

[190] Yuan H, Pang SF. [ ${ }^{125}$ I]Iodomelatonin-binding sites in the pigeon brain: binding characteristics, regional distribution and diurnal variation. J Endocrinol 1991; 128: 475-82.

[191] Hardeland R, Poeggeler B, Pappolla MA. New vistas on mitochondrial electron flux rates and aging. Cell 2008; Comment: http://www.cell.com/content/article/comments?uid=PIIS009286740 8000627

[192] Shimokawa I, Chiba T, Yamaza H, Komatsu T. Longevity genes: insights from calorie restriction and genetic longevity models. Mol Cells 2008; 26: 427-35.

[193] Guarente L. Sirtuins in aging and disease. Cold Spring Harb Symp Quant Biol 2007; 72: 483-8. 
[194] Chen D, Bruno J, Easlon E, et al. Tissue-specific regulation of SIRT1 by calorie restriction. Genes Dev 2008; 22:1753-7.

[195] Finley LW, Haigis MC. The coordination of nuclear and mitochondrial communication during aging and calorie restriction. Ageing Res Rev 2009; 8: 173-88.

[196] Lombard DB, Alt FW, Cheng HL, et al. Mammalian Sir2 homolog SIRT3 regulates global mitochondrial lysine acetylation. Mol Cell Biol 2007; 27: 8807-14.

[197] Jacobs KM, Pennington JD, Bisht KS, et al. SIRT3 interacts with the daf-16 homolog FOXO3a in the mitochondria, as well as increases FOXO3a dependent gene expression. Int J Biol Sci 2008; 4: 291-9.

[198] Hallows WC, Albaugh BN, Denu JM. Where in the cell is SIRT3?-functional localization of an $\mathrm{NAD}^{+}$-dependent protein deacetylase. Biochem J 2008; 411: e11-3.

[199] Ahn BH, Kim HS, Song S, et al. A role for the mitochondrial deacetylase Sirt3 in regulating energy homeostasis. Proc Natl Acad Sci USA 2008; 105: 14447-52.

[200] Dilova I, Easlon E, Lin SJ. Calorie restriction and the nutrient sensing signaling pathways. Cell Mol Life Sci 2007; 64: 752-67.

[201] Fulco M, Sartorelli V. Comparing and contrasting the roles of AMPK and SIRT1 in metabolic tissues. Cell Cycle 2008; 7: 366979.

[202] López-Lluch G, Irusta PM, Navas P, de Cabo R. Mitochondrial biogenesis and healthy aging. Exp Gerontol 2008; 43: 813-9.

[203] McCarty MF, Barroso-Aranda J, Contreras F. The "rejuvenatory" impact of lipoic acid on mitochondrial function in aging rats may reflect induction and activation of PPAR-gamma coactivator- $1 \alpha$. Med Hypotheses 2009; 72: 29-33.

[204] Nakahata Y, Kaluzova M, Grimaldi B, et al. The NAD ${ }^{+}$-dependent deacetylase SIRT1 modulates CLOCK-mediated chromatin remodeling and circadian control. Cell 2008; 134: 329-40.

[205] Nakahata Y, Sahar S, Astarita G, et al. Circadian control of the $\mathrm{NAD}^{+}$salvage pathway by CLOCK-SIRT1. Science 2009; 324: 654-7.
[206] McCarty MF, Barroso-Aranda J, Contreras F. AMP-activated kinase may suppress NADPH oxidase activation in vascular tissues. Med Hypotheses 2009; 72: 468-70.

[207] Jang M, Cai L, Udeani GO, et al. Cancer chemopreventive activity of resveratrol, a natural product derived from grapes. Science 1997; 275: 218-20.

[208] Wendler J, Hardeland R. Phenolic food constituents as free-radical scavengers and luminophores: I. Resveratrol. In: Hardeland R, Ed. Studies on Antioxidants and their Metabolites. Göttingen. Germany, Cuvillier 1999; pp. 38-47.

[209] Burkhardt S, Reiter RJ, Tan D-X, et al. DNA oxidatively damaged by chromium(III) and $\mathrm{H}_{2} \mathrm{O}_{2}$ is protected by melatonin, $N^{1}$-acetyl$N^{2}$-formyl-5-methoxykynuramine, resveratrol and uric acid. Int $\mathrm{J}$ Biochem Cell Biol 2001; 33: 775-83.

[210] Allard JS, Perez E, Zou S, de Cabo R. Dietary activators of Sirt1. Mol Cell Endocrinol 2009; 299: 58-63.

[211] Boily G, He XH, Pearce B, et al. SirT1-null mice develop tumors at normal rates but are poorly protected by resveratrol. Oncogene 2009; 28: 2882-93.

[212] Csiszar A, Labinskyy N, Pinto JT, et al. Resveratrol induces mitochondrial biogenesis in endothelial cells. Am J Physiol Heart Circ Physiol 2009; 297: H13-20.

[213] Feng D, Witkowski A, Smith S. Down-regulation of mitochondria acyl carrier protein in mammalian cells compromises protein lipoylation and respiratory complex I and results in cell death. J Biol Chem 2009; 284: 11436-45.

[214] Gutierrez-Cuesta J, Tajes M, Jiménez A, et al. Evaluation of potential pro-survival pathways regulated by melatonin in a murine senescence model. J Pineal Res 2008; 45: 497-505.

[215] Chang H-M, Wu, U-I, Lan C-T. Melatonin preserves longevity protein (sirtuin 1) expression in the hippocampus of total sleepdeprived rats. J Pineal Res 2009; 47: 211-20.

[216] Tajes M, Gutierrez-Cuesta J, Ortuño-Sahagun D, et al. Anti-aging properties of melatonin in an in vitro murine senescence model: involvement of the sirtuin 1 pathway. J Pineal Res 2009; 47: 22837. 